\title{
Survival Rate of Short, Locking Taper Implants with a Plateau Design: A 5-Year Retrospective Study
}

\author{
Kemal Özgür Demiralp, ${ }^{1}$ Nihat Akbulut, ${ }^{2}$ Sebnem Kursun, ${ }^{3}$ Didem Argun, \\ Nilsun Bagis, ${ }^{5}$ and Kaan Orhan ${ }^{6}$ \\ ${ }^{1}$ Ministry of Health, Public Hospitals Agency of Turkey, 06520 Ankara, Turkey \\ ${ }^{2}$ Oral and Maxillofacial Surgery Department, Faculty of Dentistry, Gaziosmanpaşa University, 60150 Tokat, Turkey \\ ${ }^{3}$ Division of Dentomaxillofacial Radiology, Ministry of Health, Bolu Oral and Dental Health Center, 14300 Bolu, Turkey \\ ${ }^{4}$ Special Clinic Practice, 06490 Ankara, Turkey \\ ${ }^{5}$ Department of Periodontology, Faculty of Dentistry, Ankara University, 06500 Ankara, Turkey \\ ${ }^{6}$ Dentomaxillofacial Radiology Department, Faculty of Dentistry, Ankara University, 06500 Ankara, Turkey
}

Correspondence should be addressed to Sebnem Kursun; sebnemkursun@yahoo.com.tr

Received 14 January 2015; Revised 27 March 2015; Accepted 2 April 2015

Academic Editor: Konstantinos Michalakis

Copyright (C) 2015 Kemal Özgür Demiralp et al. This is an open access article distributed under the Creative Commons Attribution License, which permits unrestricted use, distribution, and reproduction in any medium, provided the original work is properly cited.

\begin{abstract}
Background. Short implants have become popular in the reconstruction of jaws, especially in cases with limited bone height. Shorter implants, those with locking tapers and plateau root shapes, tend to have longer survival times. We retrospectively investigated the cumulative survival rates of Bicon short implants $(<8 \mathrm{~mm})$ according to patient variables over a 5-year period. Materials and Methods. This study included 111 consecutively treated patients with 371 implants supporting fixed or removable prosthetics. Data were evaluated to acquire cumulative survival rates according to gender, age, tobacco use, surgical procedure, bone quality, and restoration type. Statistics were performed using chi-square, Mann-Whitney, and Kruskal Wallis $\mathrm{H}$ tests. Results. The survival rate was $97.3 \%$ with, on average, 22.8 months of follow-up. Patients older than 60 years had higher failure rate than the other age groups $(P<0.05)$. Placed region, age, and bone quality had adverse effects on survival rate in the $<8 \mathrm{~mm}$ implant group with statistically significant difference $(P<0.05)$. Conclusions. Approximately 23 -month follow-up data indicate that short implants with locking tapers and plateau-type roots have comparable survival rates as other types of dental implants. However, due to limitations of study, these issues remain to be further investigated in future randomized controlled clinical trials.
\end{abstract}

\section{Introduction}

The use of short implants $(<8 \mathrm{~mm})$, especially in jaws with less bone height, has long been a source of debate and has been associated with a low success rate $[1,2]$. However, the development of implant designs such as the plateau root form [3] and implants with surface structures has increased the success rate to above $90 \%$ [1].

Primary stability, which depends on surgical technique (immediate versus normal placements, stage 1 versus stage 2) and the properties of the bone in which the implant is placed (types I, II, III, and IV), is important for dental implant success [4]. In bone of poor quality, increasing implant diameter may be the only way to increase tolerance to occlusal forces, improve initial stability, and provide a favorable stress distribution to the surrounding bone [5]. Finite element analyses have also suggested that maximum bone stress is particularly related to implant design but practically independent of implant length [6]. Successful osseointegration has been documented [7], and systemic factors such as advanced age and smoking [8] may be related to failure to achieve osseointegration and wound healing [9].

The Bicon short implant system (Bicon, LLC) is a screwless implant system. The implant and implant-abutment unit connect with a $3^{\circ}$ locking taper in a screwless system [10]. The high-friction force created by the locking taper breaks 
down the titanium oxide layer, and the metals become fused together in a cold weld [10]. This locking taper connectiontype implant with conical abutment has the potential to develop a microbial seal $[10,11]$, leading to decreased periimplant bone loss due to microbial invasion and successful osseointegration.

In the present study, we retrospectively investigated the cumulative survival rates of Bicon short implants (shorter than $8 \mathrm{~mm}$ ) and compare them with $8 \mathrm{~mm}$ implants according to patient variables in a 5 -year cohort study using radiological assessments during long-term follow-up.

\section{Methods}

2.1. Study Design and Sample. The present study was a retrospective cohort study. We retrieved patient data, including radiographs, from medical records. The cohort was composed of patients with at least one Bicon short implant $(<8 \mathrm{~mm})$ and $(8 \mathrm{~mm})$ implants placed between November 2007 and February 2012 at the Faculty of Dentistry, University of Ankara, Ankara, Turkey.

All patients provided written informed consent. Ethical approval was obtained from the Human Research Ethics Committee of our institution (clearance certificate: 13KAEK-131).

\subsection{Study Variables}

2.2.1. Demographics and Health Status. All patient data, including age, gender, and systemic conditions, were noted before the surgical procedure. Age was classified as older or younger than 60 . Patients who were categorized as being medically compromised, patients with evidence of bone disease, relevant drug consumption, skeletal asymmetries or trauma, congenital disorders, and pathological disorders of the maxilla or mandible, and syndromic patients were excluded.

2.2.2. Anatomical Variables. From patient files and radiographs, implant location and bone quality (types I-III; there were no type IV cases) were noted. Bone quality was ascertained clinically at the time of implant placement according to surgeon judgment. The two radiologist coauthors investigated patient panoramic X-rays (Figure 2) in terms of bone quality. All radiographs were taken with a conventional (Planmeca Proline, Helsinki, Finland) imaging unit at machine settings of $66-70 \mathrm{kVp}, 6 \mathrm{~mA}$ (Eastman Kodak Co., Rochester, NY, USA), or with a digital unit (Planmeca ProMax) at $66-70 \mathrm{kVp}, 8 \mathrm{~mA}$, as recommended by the manufacturer. All postsurgical radiographs were obtained as digital panoramic radiographs. The conventional film radiographs were digitized with a flatbed scanner (Epson Expression $10000 \mathrm{XL}$ ) with a transparency adapter. Digitization was performed at $300 \mathrm{dpi}$ and in grayscale. Digital films were stored in a computer database using the manufacturer's software (Dimaxis Pro, version 4.0.5, Planmeca).

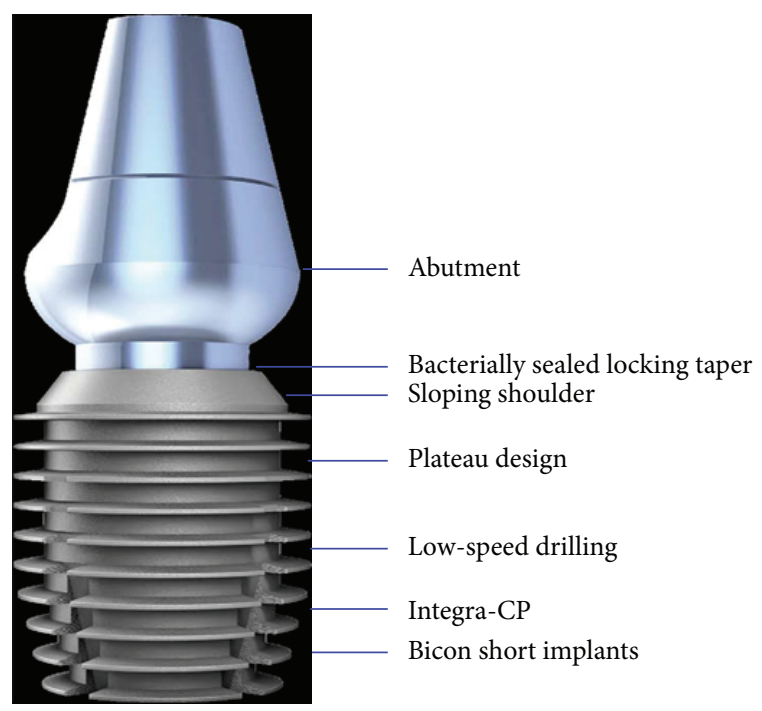

FIgURE 1: Features of the Bicon short implant.

2.2.3. Implant-Specific Variables. The Bicon Integra-CP system (Bicon, LLC) was used (Figure 1). Implant-related variables included length $(5-8 \mathrm{~mm})$, diameter $(3-5 \mathrm{~mm})$, and well size $(2-3 \mathrm{~mm})$. It was also noted whether the surgery was a two-stage surgery or an immediate or normal surgical placement. Normal implant placements were carried out in edentulous crestal bone areas. From the patient files, we also noted whether the type of restoration for each implant was a fixed or removable (overdenture) prosthesis.

2.2.4. Implant Survival Evaluation. Implant failure was the primary outcome variable. For an adequate treatment the following criteria were taken into account: clinical stability with complete function and no discomfort to the patient, no suppuration or infection present, and also no radiolucent areas around the implants in a radiographic examination $[1,7]$.

2.2.5. Data Management and Statistics. A database was created using Excel (Microsoft), with appropriate checks made to identify errors. Then the data were transferred to the SPSS (Statistical Package for the Social Sciences) software (version 15.0) for statistical analyses. Frequency and percentage distributions were calculated. Based on the results of normality tests, when examining differences between groups, the Mann-Whitney $U$ test was used in double groups with nonnormal distributions of variables. With more than two groups with nonnormal distributions of variables, the Bonferroni-corrected Kruskal-Wallis $H$-test was used. To examine dependence between variables, the chi-squared test was used. A $P$ value $<0.05$ was considered to indicate statistical significance.

\section{Results}

In total, 111 patients were treated with 371 short Bicon implants supporting fixed and removable prostheses. The mean age of the patients was 45.7 (range, $18-67$ ) years; $13.2 \%$ 


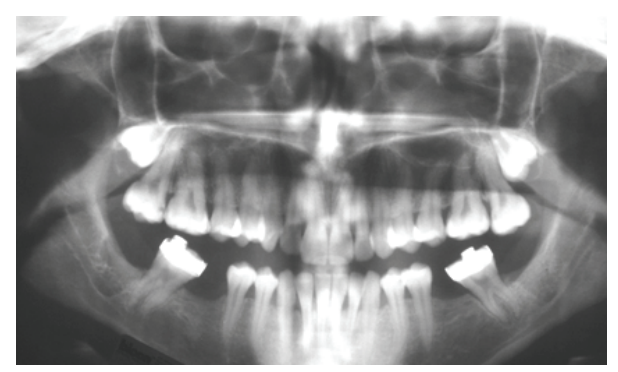

(a)

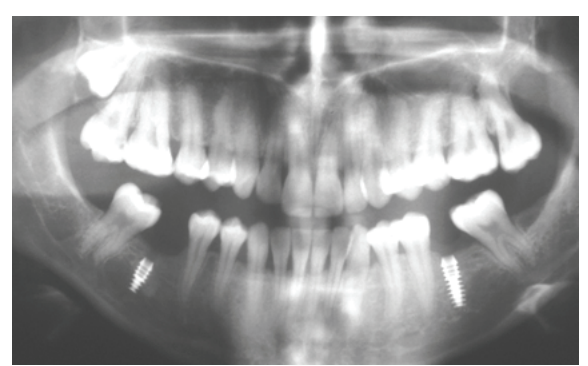

(b)

Figure 2: (a) Presurgical radiograph, (b) 6-month follow-up radiograph with $(<8 \mathrm{~mm})$ on the right and (8 mm) on the left side of the same patient.

TABLE 1: Implants placed according to patient demographics.

\begin{tabular}{|c|c|c|c|c|c|}
\hline & & $n$ (patient) & $\%$ & $n$ (implant) & $\%$ \\
\hline \multirow{3}{*}{ Gender } & Male & 64 & 57.66 & 223 & 60.11 \\
\hline & Female & 47 & 42.34 & 148 & 39.89 \\
\hline & Total & 111 & 100 & 371 & 100 \\
\hline \multirow{3}{*}{ Age } & Over 60 & 98 & 88.3 & 322 & 86.79 \\
\hline & Under 60 & 13 & 11.7 & 49 & 13.21 \\
\hline & Total & 111 & 100 & 371 & 100 \\
\hline \multirow{3}{*}{ Tobacco use } & No & 79 & 71.17 & 267 & 71.97 \\
\hline & Yes & 32 & 28.83 & 104 & 28.03 \\
\hline & Total & 111 & 100 & 371 & 100 \\
\hline
\end{tabular}

of patients were older than 60 and $86.8 \%$ were younger than 60 (Table 1). Of the patients, 47 (39.9\%) were women. All patients were in good health and $28 \%$ were smokers (Table 1). Descriptive implant variables are summarized in Table 2.

3.1. Implant Survival Findings. The mean duration of clinical follow-up was 22.8 (range, 2-51) months after surgical placement of the implants (Table 3). In total, 10 of the 371 implants failed, giving a cumulative survival rate of $97.3 \%$ with, on average, 22.8 months of follow-up (Tables 2 and 3). All failures occurred during the healing or osseointegration phase before prosthetic loading.

Detailed statistical analyses revealed that some factors (demographic, smoking, and anatomical factors) were related with implant success. Patients with implants $(<8 \mathrm{~mm})$ older than 60 years had a higher failure rate than the patients under 60 years $(P<0.05$; Table 4$)$. However, no significant difference was found for $8 \mathrm{~mm}$ implants according to age groups in terms of implant failure $(P>0.05)$. Overall, again no statistical significant difference was found according to gender groups in terms of implant failure for both $<8 \mathrm{~mm}$ and $8 \mathrm{~mm}$ groups $(P>0.05)$.

There was no significant difference $(P>0.05)$ between tobacco users and nonsmokers in terms of implant survival rate (Table 5) for both groups. However, surgical implant placement technique (immediate versus normal placements) significantly affected the survival rate of short implants $(P<$ 0.05). Implants placed using the normal surgical technique had a higher survival rate than those placed using the immediate technique (Table 6).

In Table 7, statistical significant difference was found in implant failure between implants placed in the mandibular, premolar-molar regions. It was indicated that the implants shorter than $8 \mathrm{~mm}(<8 \mathrm{~mm})$ in the mandibular premolarmolar region had higher failure rate than the others $(P<$ 0.05). Table 8 shows the implant failure rate versus bone type I, II, or III. Type II bone had higher survival rates while type III had the highest failure rate with a significant difference in implants shorter than $8 \mathrm{~mm}(<8 \mathrm{~mm})$ whereas no statistical significance was found regarding bone quality (types) in terms of implant failure for $8 \mathrm{~mm}$ implants $(P>0.05)$. Similarly, there was no effect of prosthetic rehabilitation on implant failure rate for all implant groups (Table 9).

\section{Discussion}

After loading, all of the short implants were functional with no complications. Consistent with previous studies, all implant failures were seen in the early phases of treatment $[1,12,13]$.

One of our main findings is the cumulative survival rate of $97.3 \%$ with, on average, 22.8 months of follow-up. The second major finding is the average marginal bone loss of $0.41 \mathrm{~mm}$ in the same follow-up time. Consistent with our results, Gentile et al. [2] reported a survival rate of $95.2 \%$ in patients with short implants during a 1-year follow-up. Vandeweghe et al. [14] reported a survival rate of $96.5 \%$ 
TABLE 2: Implant variables.

\begin{tabular}{|c|c|c|c|}
\hline & & $n$ & $\%$ \\
\hline \multirow{3}{*}{ Length (mm) } & $<8 \mathrm{~mm}$ & 118 & 31.81 \\
\hline & $8 \mathrm{~mm}$ & 253 & 68.19 \\
\hline & Total & 371 & 100 \\
\hline \multirow{6}{*}{ Width (mm) } & $3 \mathrm{~mm}$ & 4 & 1.08 \\
\hline & $3.5 \mathrm{~mm}$ & 76 & 20.49 \\
\hline & $4 \mathrm{~mm}$ & 62 & 16.71 \\
\hline & $4.5 \mathrm{~mm}$ & 132 & 35.58 \\
\hline & $5 \mathrm{~mm}$ & 97 & 26.15 \\
\hline & Total & 371 & 100 \\
\hline \multirow{4}{*}{ Well diameter (mm) } & $2 \mathrm{~mm}$ & 148 & 39.89 \\
\hline & $2.5 \mathrm{~mm}$ & 1 & 0.27 \\
\hline & $3 \mathrm{~mm}$ & 222 & 59.84 \\
\hline & Total & 371 & 100 \\
\hline \multirow{5}{*}{ Implant region } & Mandibular incisor region & 29 & 7.82 \\
\hline & Maxillary incisor region & 53 & 14.29 \\
\hline & Mandibular premolar-molar region & 127 & 34.23 \\
\hline & Maxillary premolar-molar region & 162 & 43.67 \\
\hline & Total & 371 & 100 \\
\hline \multirow{4}{*}{ Bone quality } & Type I & 10 & 2.70 \\
\hline & Type II & 278 & 74.93 \\
\hline & Type III & 83 & 22.37 \\
\hline & Total & 371 & 100 \\
\hline \multirow{3}{*}{ Surgical technique } & Immediate placement & 42 & 11.32 \\
\hline & Normal placement & 329 & 88.68 \\
\hline & Total & 371 & 100 \\
\hline \multirow{4}{*}{ Restoration type } & Crown & 56 & 15.09 \\
\hline & Crown-bridge & 299 & 80.59 \\
\hline & Overdenture & 16 & 4.31 \\
\hline & Total & 371 & 100 \\
\hline \multirow{3}{*}{ Implant survival } & Failed & 10 & 2.70 \\
\hline & Functional & 361 & 97.30 \\
\hline & Total & 371 & 100 \\
\hline
\end{tabular}

TABLE 3: Distribution of implant variables and follow-up time.

\begin{tabular}{|c|c|c|c|c|c|c|}
\hline & $n$ & Mean & Median & Min & $\operatorname{Max}$ & SS \\
\hline Length (mm) & 371 & 7.35 & 8 & 5 & 8 & 0.95 \\
\hline Width $(\mathrm{mm})$ & 371 & 4.33 & 4.5 & 3 & 5 & 0.55 \\
\hline Well diameter $(\mathrm{mm})$ & 371 & 2.63 & 3 & 2 & 3 & 0.47 \\
\hline Follow-up time after surgery (months) & 371 & 22.83 & 23 & 2 & 51 & 10.90 \\
\hline Follow-up time after prosthesis (months) & 371 & 17.41 & 18 & 0 & 47 & 10.93 \\
\hline
\end{tabular}

in 13 patients with short implants supporting single crowns (2 implants failed).

Short dental implants have become more popular in recent years because of increased survival and success rates due to changes in design and structural features [1-4, 9, 10, 13-17]. One of the more popular short dental implant systems is the Bicon short implant (Bicon, LLC), which has a conical, $3.0^{\circ}$ locking taper, is screwless, and has a plateau root form. The plateau root form provides some benefits in terms of healing and osseointegration, where the healing chambers become filled with a blood clot, which is eventually replaced with new bone, leading to biomechanical fixation [15]. When this process takes place as expected, it leads to significantly improved healing patterns compared to screw root form implants [15]. Plateau designs also have greater surface areas despite being shorter, maximizing osseous contact [12]. A significant advantage of having an abutmentimplant connection with a locking taper is that there are 
TABLE 4: Implant failure distribution in terms of age group.

\begin{tabular}{|c|c|c|c|c|c|c|c|c|c|}
\hline \multirow{3}{*}{\multicolumn{2}{|c|}{ Implant failure }} & \multicolumn{6}{|c|}{ Age } & \multirow{2}{*}{\multicolumn{2}{|c|}{ Statistical analysis }} \\
\hline & & \multicolumn{2}{|c|}{ Under 60} & \multicolumn{2}{|c|}{ Over 60} & \multicolumn{2}{|c|}{ Total } & & \\
\hline & & $n$ & $\%$ & $n$ & $\%$ & $n$ & $\%$ & Chi-square test & $P$ \\
\hline \multirow{3}{*}{$<8 \mathrm{~mm}$} & Failed & 2 & 1,9 & 3 & 27,3 & 5 & 4,2 & \multirow{3}{*}{ Fisher's exact test } & \multirow{3}{*}{0.006} \\
\hline & Functional & 105 & 98,1 & 8 & 72,7 & 113 & 95,8 & & \\
\hline & Total & 107 & 100 & 11 & 100 & 118 & 100 & & \\
\hline \multirow{3}{*}{$8 \mathrm{~mm}$} & Failed & 4 & 1,9 & 1 & 2,6 & 5 & 2 & \multirow{3}{*}{ Fisher's exact test } & \multirow{3}{*}{0.56} \\
\hline & Functional & 211 & 98,1 & 37 & 97,4 & 248 & 98 & & \\
\hline & Total & 215 & 100 & 38 & 100 & 253 & 100 & & \\
\hline
\end{tabular}

TABLE 5: Survival of implants according to smoking and nonsmoking groups.

\begin{tabular}{|c|c|c|c|c|c|c|c|c|c|}
\hline \multirow{3}{*}{\multicolumn{2}{|c|}{ Implant failure }} & \multicolumn{6}{|c|}{ Smoking or nonsmoking } & \multicolumn{2}{|c|}{ Chi-square test } \\
\hline & & \multicolumn{2}{|c|}{ No } & \multicolumn{2}{|c|}{ Yes } & \multicolumn{2}{|c|}{ Total } & & \\
\hline & & $n$ & $\%$ & $n$ & $\%$ & $n$ & $\%$ & & \\
\hline \multirow{3}{*}{$<8 \mathrm{~mm}$} & Failed & 3 & 3,7 & 2 & 5,6 & 5 & 4,2 & & \\
\hline & Functional & 79 & 96,3 & 34 & 94,4 & 113 & 95,8 & Fisher's exact test & 0.64 \\
\hline & Total & 82 & 100 & 36 & 100 & 118 & 100 & & \\
\hline \multirow{3}{*}{$8 \mathrm{~mm}$} & Failed & 3 & 1,6 & 2 & 2,9 & 5 & 2 & & \\
\hline & Functional & 182 & 98,4 & 66 & 97,1 & 248 & 98 & Fisher's exact test & 0.613 \\
\hline & Total & 185 & 100 & 68 & 100 & 253 & 100 & & \\
\hline
\end{tabular}

TABLE 6: Survival of implants according to surgical placement technique.

\begin{tabular}{|c|c|c|c|c|c|c|c|c|c|}
\hline \multirow{3}{*}{\multicolumn{2}{|c|}{ Implant failure }} & \multicolumn{6}{|c|}{ Surgical placement techniques } & \multicolumn{2}{|c|}{ Statistical analysis } \\
\hline & & \multicolumn{2}{|c|}{ Immediate } & \multicolumn{2}{|c|}{ Normal } & \multicolumn{2}{|c|}{ Total } & \multirow[b]{2}{*}{ Chi-square test } & \multirow[b]{2}{*}{$P$} \\
\hline & & $n$ & $\%$ & $n$ & $\%$ & $n$ & $\%$ & & \\
\hline \multirow{3}{*}{$<8 \mathrm{~mm}$} & Failed & 5 & 4,4 & 0 & 0 & 5 & 4,2 & \multirow{3}{*}{ Fisher's exact test } & \multirow{3}{*}{0.001} \\
\hline & Functional & 5 & 100 & 108 & 95,6 & 113 & 95,8 & & \\
\hline & Total & 5 & 100 & 113 & 100 & 118 & 100 & & \\
\hline \multirow{3}{*}{$8 \mathrm{~mm}$} & Failed & 4 & 10,8 & 1 & 0,5 & 5 & 2 & \multirow{3}{*}{ Fisher's exact test } & \multirow{3}{*}{0.002} \\
\hline & Functional & 33 & 89,2 & 215 & 99,5 & 248 & 98 & & \\
\hline & Total & 37 & 100 & 216 & 100 & 253 & 100 & & \\
\hline
\end{tabular}

TABLE 7: Implant failure distribution according to placed region.

\begin{tabular}{|c|c|c|c|c|c|c|c|c|c|}
\hline & & & & & $\mathrm{Im}$ & failus & & & Chi-square test \\
\hline & & & & & & onal & & & \\
\hline & & & $n$ & $\%$ & $n$ & $\%$ & $n$ & $\%$ & $P$ \\
\hline & & Mandibular incisor & 0 & 0 & 3 & 2,7 & 3 & 2,5 & \\
\hline & & Maxillary incisor & 0 & 0 & 3 & 2,7 & 3 & 2,5 & \\
\hline$<8 \mathrm{~mm}$ & Placed region & Mandibular premolar-molar & 5 & 100 & 35 & 31 & 40 & 33,9 & 0.024 \\
\hline & & Maxillary premolar-molar & 0 & 0 & 72 & 63,7 & 72 & 61 & \\
\hline & & Total & 5 & 100 & 113 & 100 & 118 & 100 & \\
\hline & & Mandibular incisor & 0 & 0 & 26 & 10,5 & 26 & 10,3 & \\
\hline & & Maxillary incisor & 2 & 40 & 48 & 19,4 & 50 & 19,8 & \\
\hline $8 \mathrm{~mm}$ & Placed region & Mandibular premolar-molar & 3 & 60 & 84 & 33,9 & 87 & 34,4 & 0.255 \\
\hline & & Maxillary premolar-molar & 0 & 0 & 90 & 36,3 & 90 & 35,6 & \\
\hline & & Total & 5 & 100 & 248 & 100 & 253 & 100 & \\
\hline
\end{tabular}


TABLE 8: Survival of implants according to bone quality.

\begin{tabular}{|c|c|c|c|c|c|c|c|c|c|}
\hline & & & \multicolumn{6}{|c|}{ Implant failure } & \multirow{3}{*}{$\begin{array}{c}\text { Chi-square test } \\
P \\
P\end{array}$} \\
\hline & & & \multicolumn{2}{|c|}{ Failed } & \multicolumn{2}{|c|}{ Functional } & \multicolumn{2}{|c|}{ Total } & \\
\hline & & & $n$ & $\%$ & $n$ & $\%$ & $n$ & $\%$ & \\
\hline \multirow{4}{*}{$<8 \mathrm{~mm}$} & \multirow{4}{*}{ Bone quality } & Type I & 0 & 0 & 1 & 0,9 & 1 & 0,8 & \multirow{4}{*}{0.044} \\
\hline & & Type II & 1 & 20 & 94 & 83,2 & 95 & 80,5 & \\
\hline & & Type III & 4 & 80 & 18 & 15,9 & 22 & 18,6 & \\
\hline & & Total & 5 & 100 & 113 & 100 & 118 & 100 & \\
\hline \multirow{4}{*}{$8 \mathrm{~mm}$} & \multirow{4}{*}{ Bone quality } & Type I & 0 & 0 & 9 & 3,6 & 9 & 3,6 & \multirow{4}{*}{0.25} \\
\hline & & Type II & 2 & 40 & 181 & 73 & 183 & 72,3 & \\
\hline & & Type III & 3 & 60 & 58 & 23,4 & 61 & 24,1 & \\
\hline & & Total & 5 & 100 & 248 & 100 & 253 & 100 & \\
\hline
\end{tabular}

TABLE 9: Survival of implants according to prosthetic rehabilitation.

\begin{tabular}{|c|c|c|c|c|c|c|c|c|c|}
\hline & & & \multicolumn{6}{|c|}{ Implant failure } & \multirow{3}{*}{$\begin{array}{c}\text { Chi-square test } \\
P\end{array}$} \\
\hline & & & \multicolumn{2}{|c|}{ Failed } & \multicolumn{2}{|c|}{ Functional } & \multicolumn{2}{|c|}{ Total } & \\
\hline & & & $n$ & $\%$ & $n$ & $\%$ & $n$ & $\%$ & \\
\hline \multirow{3}{*}{$<8 \mathrm{~mm}$} & \multirow{3}{*}{ Prosthetic rehabilitation } & Crown & 0 & 0 & 21 & 18,9 & 21 & 18,9 & \multirow{3}{*}{0.99} \\
\hline & & Crown-bridge & 0 & 0 & 90 & 81,1 & 90 & 81,1 & \\
\hline & & Total & $\mathbf{0}$ & $\mathbf{0}$ & 111 & 100 & 111 & 100 & \\
\hline \multirow{4}{*}{$8 \mathrm{~mm}$} & \multirow{4}{*}{ Prosthetic rehabilitation } & Crown & 0 & 0 & 28 & 11,7 & 28 & 11,7 & \multirow{4}{*}{1} \\
\hline & & Crown-bridge & 1 & 100 & 195 & 81,6 & 196 & 81,7 & \\
\hline & & Overdenture & 0 & 0 & 16 & 6,7 & 16 & 6,7 & \\
\hline & & Total & 1 & 100 & 239 & 100 & 240 & 100 & \\
\hline
\end{tabular}

no screws that can loosen or fracture or other component failures. It also seals the margin of the abutment-crownimplant interface, which can harbor bacteria [10]. Because of these benefits, Bicon short implants $(<8 \mathrm{~mm})$ were used to rehabilitate the patients in the present study.

Vehemente et al. [18], using the same type of implant as in the present study, reported 12- and 60-month survival rates of $95.2 \%$ and $90.2 \%$, respectively. Rossi et al. [19] reported a survival rate of $95 \%$ in a cohort study of $6 \mathrm{~mm}$ implants with 24 months of follow-up. Finally, many other studies have reported survival rates of short implants ranging from $88 \%$ to $100 \%[1,4,9,12,13]$.

In the present study, implants in patients over 60 years old had a lower survival rate $(91.84 \%)$ than those in younger patients for $<8 \mathrm{~mm}$ implants $(98.14 \%, P<0.05)$. These findings may be related to systemic factors that decrease vascularity or contribute to delayed wound healing, such as those seen in the elderly and smokers [8, 9]. In contrast, Gentile et al. [2] reported that the mean age of patients at implant placement did not affect the survival rate of implants.

In the present study, surgical procedures affected the survival rate. Implants that were placed using the normal surgical technique had a higher survival rate $(P<0.05)$ than those placed using the immediate surgical technique for both $<8 \mathrm{~mm}$ and $8 \mathrm{~mm}$ implants. Prosthetic loadings were conducted 3-8 months after implant placement, and two-stage surgeries were the other standardized techniques used. Immediate placement of implants has several advantages: fewer surgical interventions, shorter treatment time, ideal three-dimensional implant positioning, presumptive preservation of alveolar bone at the side of tooth extraction, and soft tissue esthetic features [20]. In contrast with the present findings, most studies have suggested no difference between immediate and delayed surgical placement of short implants in terms of survival rate [20-23]. In a 2-year followup study by Palattella et al. [22], 16 patients received single tooth replacement with immediate implants and a control group received implants at healed sites; they did not find a statistically significant difference in marginal bone loss between the test and control groups. Other studies have reported similar results $[20,22,24]$.

In the present study, survival rate factors including gender, tobacco usage, and restoration type did not affect the survival rate of implants but placed region, age, and bone quality did $(P<0.05)$. Consistent with the present findings, Kumar et al. [8] reported that smoking was not related to implant survival or the osseointegration process, especially when using surface-modified dental implants, as in this study. The fact that smoking did not affect the survival rate may have been due to the short follow-up time. Many studies have reported a relationship between smoking and osseointegration failure $[8,9]$. Various reports have correlated smoking with poor-quality bone, type IV [8]. Such bone may lower the primary stability of implants. Thus, using surface-modified implants with acceptable primary stability in poorer-quality bone, such as the HA-coated implants used in this study, may be better. 
We also found no statistically significant differences $(P<$ 0.05 ) between prosthesis types in terms of survival rate of the implant especially between single crown and bridge restorations. Patients restored with crown-bridges had higher degrees of survival rate than those restored with crowns. A possible reason may be the occurrence of lateral or overload application [25]. Aglietta et al. [26] reported that singleunit crowns and short-span fixed dental prostheses with cantilever-supported implants did not show any difference in survival of the implant. Similarly, Naert et al. [27] found that the use of subsequently situated single-implant crowns to restore an edentulous space did not lead to more marginal bone loss than around splinted implants.

In conclusion, using HA-coated, short $(\leq 8 \mathrm{~mm})$, plateautype, locking taper, screwless implants, the cumulative survival rate was $97.3 \%$ with an average follow-up of 22.83 months, a satisfactory result. However, placed region, age, and bone quality had adverse effects on survival rate. Randomized controlled clinical trials with longer follow-up should be conducted to determine the cumulative survival rate and benefits of short implants in a grander context.

\section{Conflict of Interests}

The authors declare that they have no competing interests.

\section{References}

[1] P. Maló, M. D. A. Nobre, and B. Rangert, "Short implants placed one-stage in maxillae and mandibles: a retrospective clinical study with 1 to 9 years of follow-up," Clinical Implant Dentistry and Related Research, vol. 9, no. 1, pp. 15-21, 2007.

[2] M. A. Gentile, S.-K. Chuang, and T. B. Dodson, "Survival estimates and risk factors for failure with $6 \times 5.7-\mathrm{mm}$ implants," The International Journal of Oral \& Maxillofacial Implants, vol. 20, no. 6, pp. 930-937, 2005.

[3] M. Suzuki, M. D. Calasans-Maia, C. Marin et al., "Effect of surface modifications on early bone healing around plateau root form implants: an experimental study in rabbits," Journal of Oral and Maxillofacial Surgery, vol. 68, no. 7, pp. 1631-1638, 2010.

[4] F. G. Draenert, K. Sagheb, K. Baumgardt, and P. W. Kämmerer, "Retrospective analysis of survival rates and marginal bone loss on short implants in the mandible," Clinical Oral Implants Research, vol. 23, no. 9, pp. 1063-1069, 2012.

[5] H. Kido, E. E. Schulz, A. Kumar, J. Lozada, and S. Saha, "Implant diameter and bone density: effect on initial stability and pull-out resistance," The Journal of Oral Implantology, vol. 23, no. 4, pp. 163-169, 1997.

[6] L. Pierrisnard, F. Renouard, P. Renault, and M. Barquins, "Influence of implant length and bicortical anchorage on implant stres distribution," Clinical Implant Dentistry and Related Research, vol. 5, no. 4, pp. 254-262, 2003.

[7] R. Adell, U. Lekholm, B. Rockler, and P. I. Brånemark, "A 15year study of osseointegrated implants in the treatment of the edentulous jaw," International Journal of Oral Surgery, vol. 10, no. 6, pp. 387-416, 1981.

[8] A. Kumar, R. A. Jaffin, and C. Berman, "The effect of smoking on achieving osseointegration of surface-modified implants: a clinical report," International Journal of Oral and Maxillofacial Implants, vol. 17, no. 6, pp. 816-819, 2002.
[9] F. Pieri, N. N. Aldini, M. Fini, C. Marchetti, and G. Corinaldesi, "Preliminary 2-year report on treatment outcomes for 6-mmlong implants in posterior atrophic mandibles," The International Journal of Prosthodontics, vol. 25, no. 3, pp. 279-289, 2012.

[10] R. A. Urdaneta, M. Marincola, M. Weed, and S.-K. Chuang, "A screwless and cementless technique for the restoration of single-tooth implants: a retrospective cohort study," Journal of Prosthodontics, vol. 17, no. 7, pp. 562-571, 2008.

[11] S. Dibart, M. Warbington, M. F. Su, and Z. Skobe, "In vitro evaluation of the implant-abutment bacterial seal: the locking taper system," International Journal of Oral and Maxillofacial Implants, vol. 20, no. 5, pp. 732-737, 2005.

[12] R. Goené, C. Bianchesi, M. Hüerzeler et al., "Performance of short implants in partial restorations: 3-year follow-up of Osseotite implants," Implant Dentistry, vol. 14, no. 3, pp. 274280, 2005.

[13] D. Lops, E. Bressan, G. Pisoni, N. Cea, B. Corazza, and E. Romeo, "Short implants in partially edentulous maxillae and mandibles: a 10 to 20 years retrospective evaluation," International Journal of Dentistry, vol. 2012, Article ID 351793, 8 pages, 2012.

[14] S. Vandeweghe, R. de Ferrerre, A. Tschakaloff, and H. de Bruyn, "A wide-body implant as an alternative for sinus lift or bone grafting," Journal of Oral and Maxillofacial Surgery, vol. 69, no. 6, pp. e67-e74, 2011.

[15] P. G. Coelho, M. Suzuki, M. V. M. Guimaraes et al., "Early bone healing around different implant bulk designs and surgical techniques: a study in dogs," Clinical Implant Dentistry and Related Research, vol. 12, no. 3, pp. 202-208, 2010.

[16] R. A. Urdaneta and M. Marincola, “The integrated abutment Crown, a screwless and cementless restoration for singletooth implants: a report on a new technique: techniques and technologies," Journal of Prosthodontics, vol. 16, no. 4, pp. 311318, 2007.

[17] R. A. Urdaneta, J. Leary, W. Lubelski, K. M. Emanuel, and S.-K. Chuang, "The effect of implant size $5 \times 8 \mathrm{~mm}$ on crestal bone levels around single-tooth implants," Journal of Periodontology, vol. 83, no. 10, pp. 1235-1244, 2012.

[18] V. A. Vehemente, S.-K. Chuang, S. Daher, A. Muftu, and T. B. Dodson, "Risk factors affecting dental implant survival.," The Journal of oral implantology, vol. 28, no. 2, pp. 74-81, 2002.

[19] F. Rossi, E. Ricci, C. Marchetti, N. P. Lang, and D. Botticelli, "Early loading of single crowns supported by 6-mm-long implants with a moderately rough surface: a prospective 2-year follow-up cohort study," Clinical Oral Implants Research, vol. 21, no. 9, pp. 937-943, 2010.

[20] J. Ortega-Martínez, T. Pérez-Pascual, S. Mareque-Bueno, F. Hernández-Alfaro, and E. Ferrés-Padró, "Immediate implants following tooth extraction. A systematic review," Medicina Oral, Patologia Oral y Cirugia Bucal, vol. 17, no. 2, pp. e251-e261, 2012.

[21] S. Annibali, M. P. Cristalli, D. Dell'Aquila, I. Bignozzi, G. La Monaca, and A. Pilloni, "Short dental implants: a systematic review," Journal of Dental Research, vol. 91, no. 1, pp. 25-32, 2012.

[22] P. Palattella, F. Torsello, and L. Cordaro, "Two-year prospective clinical comparison of immediate replacement vs. immediate restoration of single tooth in the esthetic zone," Clinical Oral Implants Research, vol. 19, no. 11, pp. 1148-1153, 2008.

[23] L. Schropp, L. Kostopoulos, A. Wenzel, and F. Isidor, "Clinical and radiographic performance of delayed-immediate singletooth implant placement associated with peri-implant bone 
defects. A 2-year prospective, controlled, randomized followup report," Journal of Clinical Periodontology, vol. 32, no. 5, pp. 480-487, 2005.

[24] J. A. H. Lindeboom, Y. Tjiook, and F. H. M. Kroon, "Immediate placement of implants in periapical infected sites: a prospective randomized study in 50 patients," Oral Surgery, Oral Medicine, Oral Pathology, Oral Radiology and Endodontology, vol. 101, no. 6, pp. 705-710, 2006.

[25] K. Akça and H. Iplikcioğlu, "Finite element stress analysis of the effect of short implant usage in place of cantilever extensions in mandibular posterior edentulism," Journal of Oral Rehabilitation, vol. 29, no. 4, pp. 350-356, 2002.

[26] M. Aglietta, V. Iorio Siciliano, A. Blasi et al., "Clinical and radiographic changes at implants supporting single-unit crowns (SCs) and fixed dental prostheses (FDPs) with one cantilever extension. A retrospective study," Clinical Oral Implants Research, vol. 23, no. 5, pp. 550-555, 2012.

[27] I. Naert, G. Koutsikakis, M. Quirynen, J. Duyck, D. van Steenberghe, and R. Jacobs, "Biologic outcome of implantsupported restorations in the treatment of partial edentulism. Part 2: a longitudinal radiographic evaluation," Clinical Oral Implants Research, vol. 13, no. 4, pp. 390-395, 2002. 


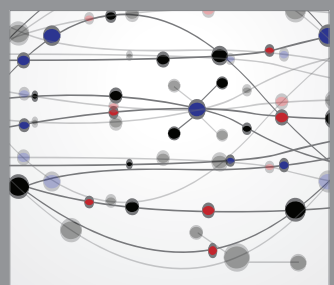

The Scientific World Journal
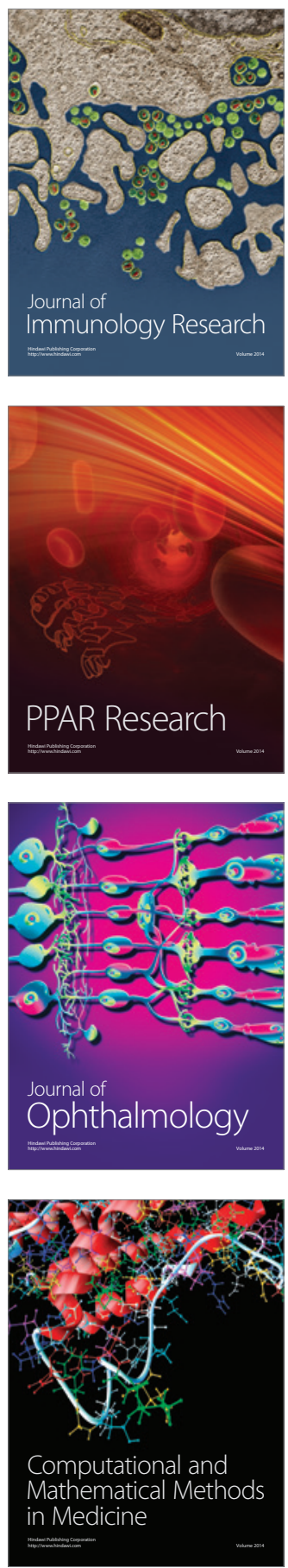

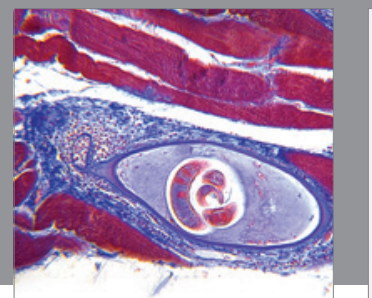

Gastroenterology

Research and Practice
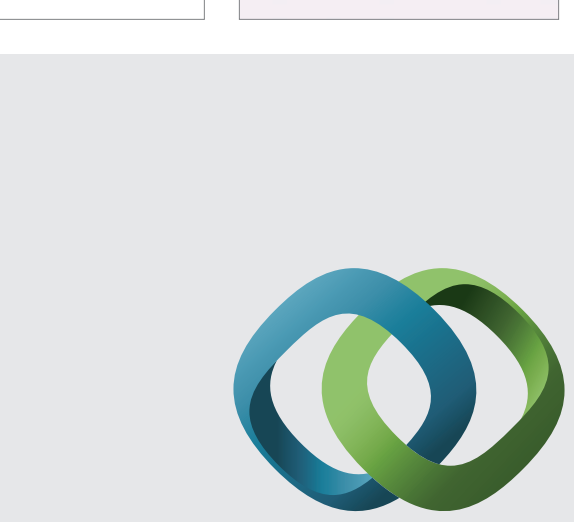

\section{Hindawi}

Submit your manuscripts at

http://www.hindawi.com
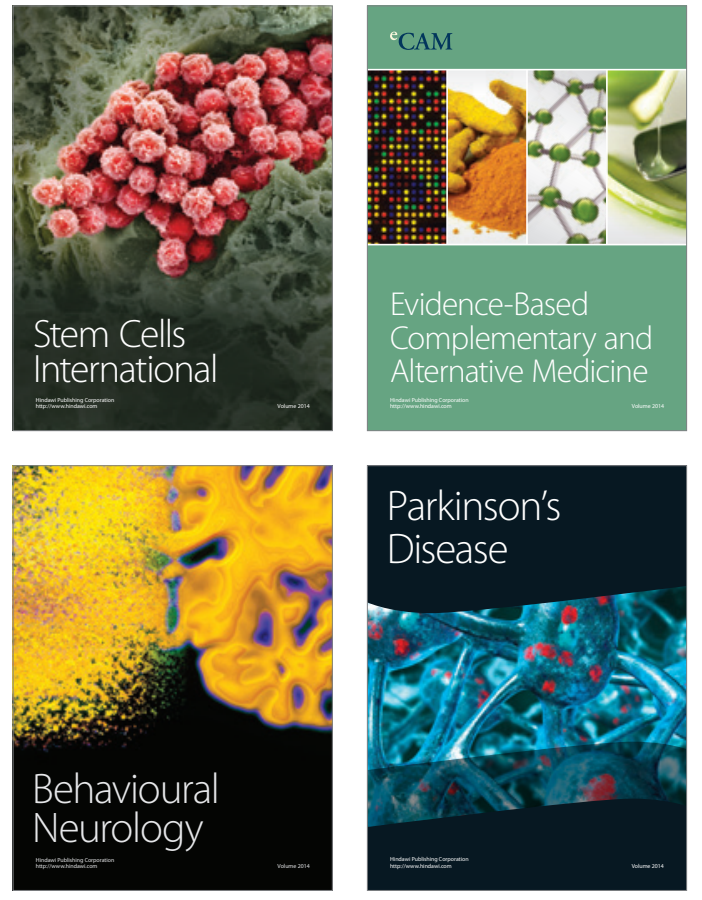
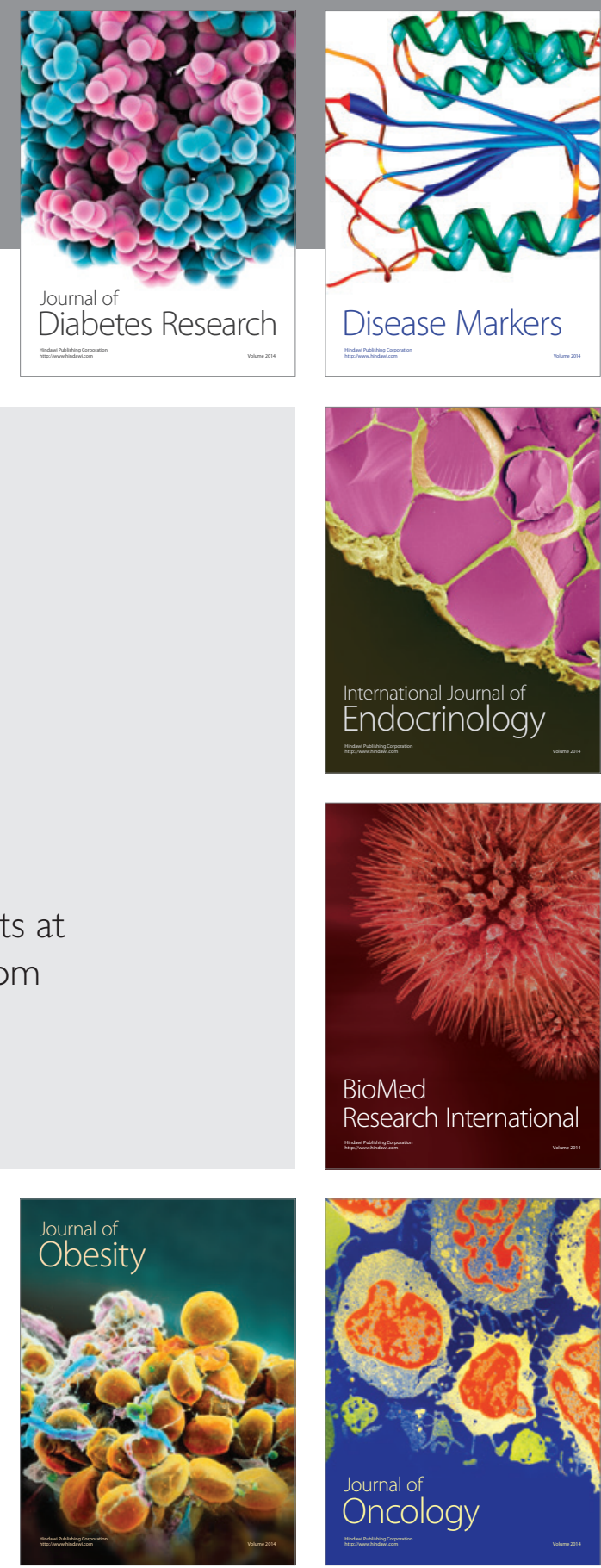

Disease Markers
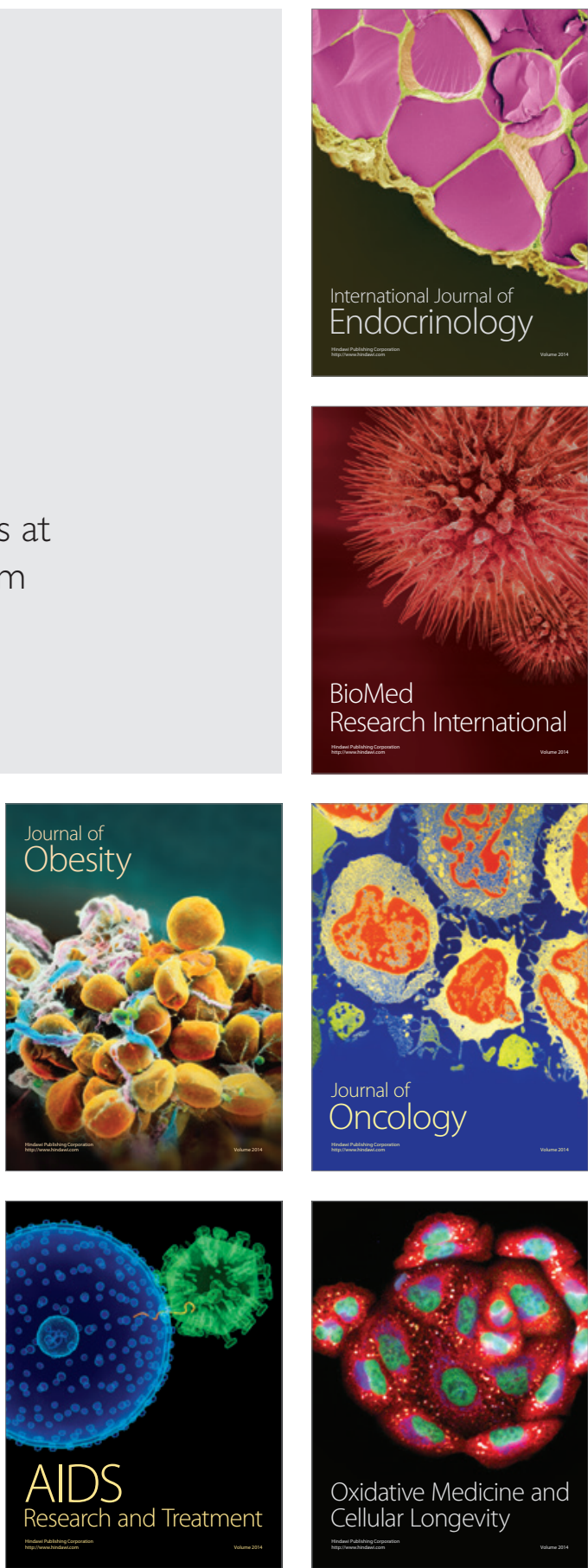